\section{'Green Dixie Blackeye', a Green Cotyledon, Blackeye-type Southernpea}

\author{
Richard L. Fery ${ }^{1}$ \\ U.S. Vegetable Laboratory, Agricultural Research Service, U.S. Department \\ of Agriculture, 2875 Savannah Highway, Charleston, SC 29414-5334
}

Additional index words. Vigna unguiculata, cowpea, blackeye bean, blackeye pea, vegetable breeding

'Green Dixie Blackeye' is a new southernpea [Vigna unguiculata (L.) Walp.] that was released on 28 Apr. 2000 by the U.S. Dept. of Agriculture, Agricultural Research Service (USDA, ARS). The new cultivar produces excellent yields of blackeye-type peas that can be harvested at the dry stage of maturity without loss of the pea's fresh green color. 'Green Dixie Blackeye' is the first blackeye-type southernpea to be released that exhibits the green cotyledon phenotype. It was developed for use by home gardeners and the dry-pack bean industry.

\section{Origin}

'Green Dixie Blackeye' was developed over a 10-year period using a pedigree breeding procedure that included a single cross and repeated single-plant selections (Fig. 1). The original cross involved 'Bettergreen', a creamtype pea with green-colored cotyledons, and 'Bettergro Blackeye', ablackeye-type pea with cream-colored cotyledons (Fery and Dukes, 1993; Fery et al., 1993). Intense selection pressure was applied in the $\mathrm{F}_{2}$ through $\mathrm{F}_{9}$ generations for the green cotyledon phenotype and blackeye-type seed characteristics. 'Green Dixie Blackeye' originated as a bulk of an $\mathrm{F}_{9}$ population grown in 1994.

\section{Description}

'Green Dixie Blackeye' has a high bushy plant habit (Table 1). It produces dry pods at Charleston, S.C., in $\approx 71 \mathrm{~d}, 9 \mathrm{~d}$ later than 'Bettergro Blackeye' (Table 2). Flower color is predominately white; the top center of the standard is lightly pigmented (purple), the base of the standard is yellow, and the wing is moderately pigmented (purple) on the back surface. There is a tendency for slight pigmentation (purple) on the stems, at the base of the branches, at the top of the petioles, and at the base and tip of the peduncles. 'Green Dixie Blackeye' has a darker green foliage color than 'Bettergro Blackeye'. Pod set is concentrated, and the pods are borne at foliage level in a scattered fashion. Dry pods are attached to the peduncles in a pendant fashion, and each peduncle typically produces two pods.

Received for publication 27 Dec. 2000. Accepted for publication 6 May 2001. The technical assistance of F.P. Maguire is gratefully acknowledged. ${ }^{1}$ Research Geneticist.

Fig. 1. Pedigree of 'Green Dixie Blackeye' southernpea. $\mathrm{cm}$ between rows.
A typical 'Green Dixie Blackeye' pod is slightly curved, $\approx 21 \mathrm{~cm}$ long, and contains $\approx 14$ peas (Fig. 2). Pod color is light green when immature, light green with a tendency for slight pigmentation (purple) on the tip when ready for mature-green harvest, and light straw color when dry. The oblong shape of dry 'Green Dixie Blackeye' peas is quite similar to the shape of dry 'Bettergro Blackeye' peas. 'Green Dixie Blackeye' peas have a smooth seedcoat and are somewhat larger than 'Bettergro Blackeye' peas (weight per 100 dry peas: 'Green Dixie Blackeye', $15.6 \mathrm{~g}$; and 'Bettergro Blackeye', $14.4 \mathrm{~g}$ ). Like 'Bettergro

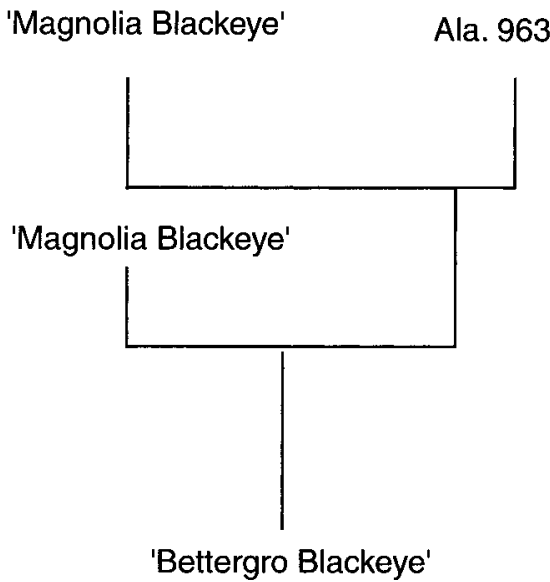

Ala. 963.8

'Floricream'

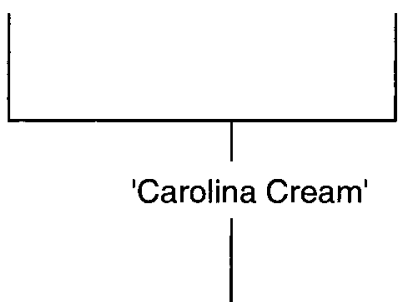

Pure line selection of a green cotyledon mutant

'Bettergreen'

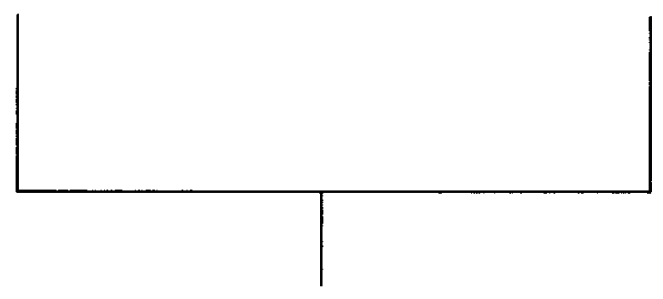

'Green Dixie Blackeye'

Table 1. Plant height, plant width, peduncle length, pod length, and number of peas per pod for 'Green Dixie Blackeye' and 'Bettergro Blackeye' southernpeas, Charleston, S.C., 1999. ${ }^{\text {. }}$

\begin{tabular}{|c|c|c|c|c|c|}
\hline \multirow[b]{2}{*}{ Cultivar } & \multicolumn{2}{|c|}{ Plant } & \multirow{2}{*}{$\begin{array}{c}\text { Peduncle } \\
\text { length } \\
(\mathrm{cm})\end{array}$} & \multirow{2}{*}{$\begin{array}{c}\text { Pod } \\
\text { length } \\
(\mathrm{cm})\end{array}$} & \multirow{2}{*}{$\begin{array}{c}\text { Peas/ } \\
\text { pod } \\
\text { (no.) }\end{array}$} \\
\hline & $\begin{array}{l}\text { Height } \\
(\mathrm{cm})\end{array}$ & $\begin{array}{c}\text { Width } \\
(\mathrm{cm})\end{array}$ & & & \\
\hline Green Dixie Blackeye & $67 a^{y}$ & $68 \mathrm{a}$ & $41 \mathrm{a}$ & $21.0 \mathrm{a}$ & $14.0 \mathrm{a}$ \\
\hline Bettergro Blackeye & $62 \mathrm{a}$ & $64 \mathrm{a}$ & $37 \mathrm{a}$ & $18.6 \mathrm{~b}$ & $13.4 \mathrm{a}$ \\
\hline
\end{tabular}

${ }^{2}$ Trial planted on 2 June 1999. The experimental design was a randomized complete block with 10 replications. Each plot was space-planted, 18 hills per plot, three seeds per hill, $30 \mathrm{~cm}$ between hills, and 102

${ }^{y}$ Mean separation within columns by Duncan's multiple range test, $P \leq 0.05$. 
Table 2. Number of days to harvest, weight per 100 dry peas, and dry pea yield for 'Green Dixie Blackeye' and 'Bettergro Blackeye' southernpeas grown in spring trials, Charleston, S.C., 1997 and 1998.

\begin{tabular}{|c|c|c|c|}
\hline Cultivar & $\begin{array}{c}\text { Days to harvest } \\
\text { (no.) }\end{array}$ & $\begin{array}{c}\text { Wt/100 dry peas } \\
(\mathrm{g})\end{array}$ & $\begin{array}{c}\text { Dry pea yiel } \\
\left(\mathrm{kg} \cdot \mathrm{ha}^{-1}\right)\end{array}$ \\
\hline \multicolumn{4}{|c|}{ Spring 1997} \\
\hline Green Dixie Blackeye & $74.0 \mathrm{a}^{\mathrm{y}}$ & $15.4 \mathrm{a}$ & $1150 \mathrm{a}$ \\
\hline Bettergro Blackeye & $65.0 \mathrm{~b}$ & $14.0 \mathrm{~b}$ & $993 \mathrm{~b}$ \\
\hline \multicolumn{4}{|c|}{ Spring 1998} \\
\hline Green Dixie Blackeye & $67.7 \mathrm{a}$ & $15.7 \mathrm{a}$ & $1353 \mathrm{a}$ \\
\hline Bettergro Blackeye & $58.3 \mathrm{~b}$ & $14.7 \mathrm{~b}$ & 896 b \\
\hline \multicolumn{4}{|c|}{ Combined analysis of both trials ${ }^{x}$} \\
\hline Green Dixie Blackeye & $70.9 \mathrm{a}^{\mathrm{Ns}}$ & $15.6 \mathrm{a}^{\mathrm{NS}}$ & $1251 \mathrm{a}^{*}$ \\
\hline Bettergro Blackeye & $61.7 \mathrm{~b}$ & $14.4 \mathrm{~b}$ & $944 \mathrm{~b}$ \\
\hline
\end{tabular}

${ }^{2}$ Spring 1997 and 1998 trials planted on 2 June and 27 May, respectively. The experimental design of each trial was a randomized complete block with 10 replications. Results of combined analyses of both trials indicated a significant cultivar $\times$ trial interaction for dry pea yield. Consequently, results are presented for both single trail and combined analyses to aid interpretation.

${ }^{y}$ Mean separation within columns and trials by Duncan's multiple range test, $P \leq 0.05$.

Ns, "Nonsignificant or significant interaction between cultivar and trial at $P \leq 0.05$, respectively.

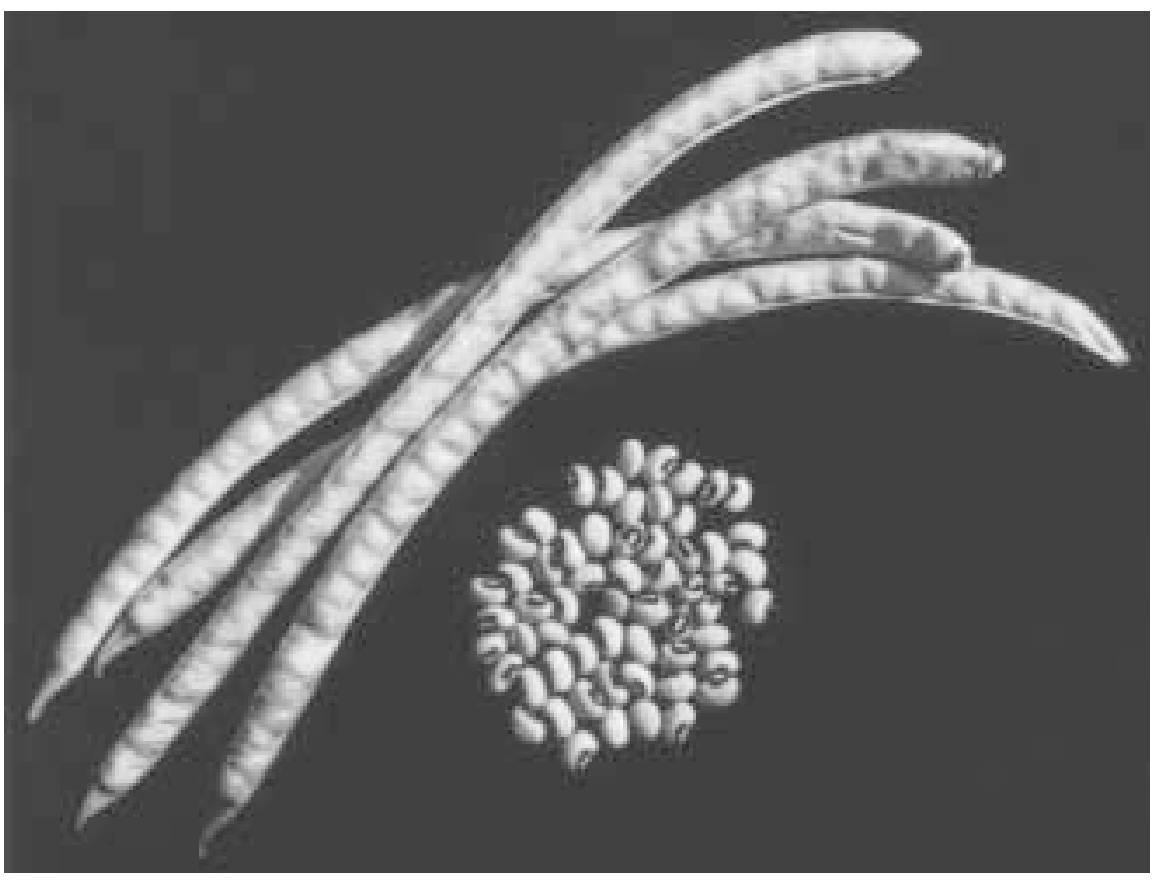

Fig. 2. Pods and peas of 'Green Dixie Blackeye' southernpea. harvest pea size and blanched in boiling water for 3 min exhibit a near-fresh green color; similarly treated 'Bettergro Blackeye' peas exhibit a cream color.

'Green Dixie Blackeye' is recommended for use by home gardeners and the dry-pack bean industry. The peas can be harvested not only fresh for immediate consumption or storage in home freezers, but also when fully dry for storage or sale as an attractive dry pack. The dry peas can be imbibed to restore a nearfresh green color.

\section{Availability}

Breeder's seed of 'Green Dixie Blackeye' has been released to seed producers. Small samples of 'Green Dixie Blackeye' breeder's seed are available from the author for distribution to all interested research personnel. Genetic material of this release will be deposited in the National Plant Germplasm System, where it will be available for research purposes, including the development and commercialization of new cultivars. It is requested that appropriate recognition of source be given when this germplasm contributes to research or development of a new breeding line or cultivar.

\section{Literature Cited}

Fery, R.L. and P.D. Dukes. 1993. 'Bettergro Blackeye' southernpea. HortScience 28:62-63.

Fery, R.L. and P.D. Dukes. 1994. Genetic analysis of the green cotyledon trait in southernpea [Vigna unguiculata (L.) Walp.]. J. Amer. Soc. Hort. Sci. 119:1054-1056.

Fery, R.L., P.D. Dukes, and F.P. Maguire. 1993. 'Bettergreen' southernpea. HortScience 28:856. 